\title{
PEDAGOGIA HISTÓRICO-CRÍTICA, PESQUISA E PRÁTICA DOCENTE NO ENSINO DE BIOLOGIA ${ }^{1}$
}

Ao longo da minha trajetória profissional, inúmeras foram as motivações que levaram ao desenvolvimento da pesquisa que relato nesse evento, que é fruto de minha tese de doutorado “A Pedagogia Histórico-crítica e prática docente de ensino de Biologia, desenvolvida em 2017 (CAMPOS, 2017).

A primeira motivação, trata-se do constante vínculo teórico com a Pedagogia históricocrítica e a participação do Grupo de pesquisa "Formação e ação de professores de ciências e de educadores ambientais" conduzido pelo Prof. Dr. Renato Eugênio da Silva Diniz e pela Profa. Dra. Luciana Maria Lunardi Campos, que também orientou e apoiou todo o desenvolvimento desse trabalho.

Um segundo ponto de motivação, é claro, trata da própria formação teórica adquirida nesse percurso, como licenciada em Ciências Biológicas, pedagoga e mestre em Educação para a Ciência e, na atuação como professora, na prática diária em sala de aula.

Todos esses pontos convergem para o que posso considerar como ponto chave de motivação: as incongruências observadas entre a teoria proposta pela Secretaria da Educação do Estado de São Paulo, o construtivismo, e a realidade do meu alunato.

Em outras palavras, esse trabalho de doutorado parte da crítica à postura teórica e metodológica das pedagógicas construtivistas assumidas pela Secretaria da Educação do Estado de São Paulo, e da defesa de uma perspectiva de ensino atenta às condições reais de ensino, uma perspectiva que busca a formação humana por meio da socialização do conhecimento, de uma concepção materialista histórico dialética: a Pedagogia Histórico-crítica (PHC).

Assim, provoco vocês com as seguintes questões: sempre que abordo a questão da Pedagogia Histórico-crítica em sala de aula, escuto o movimento contrário e conservador do atual magistério de "ah, mas na prática a teoria é outra" ou "ah, isso não dá certo não, no dia a dia da escola".

\footnotetext{
${ }^{1}$ Mesa Redonda no I Simpósio - Materialismo Histórico Dialético em Pesquisa em Ensino de Ciências e Educação Ambiental - Bauru, 18 de maio de 2018.
} 
Então, como professora da Secretaria da Educação do Estado de São Paulo, ou seja, professora efetiva de Biologia da rede Estadual e, respaldada no conhecimento teórico, me senti desafiada para colocar a Pedagogia Histórico-crítica à prova lá na sala de aula, lá na escola pública de bairro periférico, com a sobrecarga de aulas de um professor padrão: vamos lá, vamos ver se dá certo tudo isso.

A minha tese vem justamente desenvolver essa temática, "A Perspectiva Históricocrítica e Prática Docente de Ensino de Biologia” (CAMPOS, 2017). O ponto de partida deste estudo é, portanto, a defesa da viabilidade da Pedagogia Histórico-crítica do estado de São Paulo, na sala de aula, nas condições reais de trabalho.

O objetivo do trabalho de pesquisa, que destaco aqui para vocês foi compreender como se produz concretamente uma prática pedagógica na perspectiva da Pedagogia Histórico Crítica, no ensino de Biologia, analisando as forças reais que procedem, determinam e ressignificam o desenvolvimento desta prática como fenômeno histórico e social e suas contradições.

O que é significa tudo isso? É exatamente essa ideia de observar quais questões estão colocadas ali no dia a dia, quais são as contradições encontradas nesse processo de ser professor, ser pesquisador e trabalhar com o materialismo histórico dialético lá na escola pública. Mesmo no contexto dos caderninhos (material didático Caderno do Professor e Caderno do Aluno), no contexto do construtivismo que tem se aplicado no estado de São Paulo.

Simplificadamente, optei por estudar, preparar um material de intervenção de didática, ir até a escola, aplicar com meus alunos a Pedagogia Histórico-crítica, com conteúdos escolares clássicos de taxonomia e sistemática biológica na perspectiva histórico crítica e, portanto, dentro de uma concepção de mundo materialista histórico dialética.

Escolhi taxonomia e sistemática biológica para trabalhar a Pedagogia Histórico-crítica e o ensino. Por quê?

Ao iniciarmos o estudo da Pedagogia Histórico-crítica no início do nosso grupo de pesquisa, "Formação e ação de professores de ciências e de educadores ambientais", estávamos nos perguntando se existiam conteúdos difíceis, ou até mesmo impossíveis de se trabalhar dentro da perspectiva.

Digo isso, porque era fácil perceber que alguns conteúdos ficam mais próximos de promover contextualização. Era possível observar com facilidade o retorno à prática social em conteúdos que, por exemplo, trabalham a educação ambiental. Nestes conteúdos, conseguimos 
ver repercussão social imediata, conseguimos ver com facilidade como é possível o desenvolvimento de uma perspectiva crítica emancipatória.

Mas me inquietava pensar em como trabalhar aqueles conteúdos extremamente específicos de uma determinada disciplina. Como os conteúdos extremamente específicos da Biologia poderiam ser trabalhados nessa mesma perspectiva?

Ao entrar em contato com o trabalho da colega Thalita Liporini (LIPORINI, 2016), nas discussões promovidas no Grupo de Pesquisa, pude perceber na Sistemática e a Taxonomia Biológica um bom desafio para trabalhar essa inquietação.

Isso porque a Sistemática e a Taxonomia Biológica além de terem ampla importância histórica também podem ser consideradas como responsáveis por integrar a Biologia como campo de conhecimento (LIPORINI, 2016).

Sem dúvida, trata-se de um conteúdo clássico, de relevância histórica, duradora, e é claro, de difícil percepção imediata de como se daria esse retorno à prática social, como esses conteúdos de Sistemática e a Taxonomia Biológica seriam capazes de modificar-se em elementos de transformação social.

Para quem não é da área da biologia, taxonomia e sistemática são áreas de conhecimento que trabalham o agrupamento de organismos em categorias naturais em função de características compartilhadas, sejam elas morfológicas, genéticas, etc.

Ou seja, não há dúvidas sobre o reconhecimento da Sistemática e a Taxonomia Biológica como conteúdo clássico pelos autores do ensino de Ciências e de pertinência dessa área como conhecimento científico socialmente desenvolvido e seu estimado valor histórico à humanidade.

No entanto, a provocação que propus neste trabalho é: Como é que eu vou trabalhar tais conteúdos alinhados à perspectiva crítica, materialista e marxista?

É em busca da resposta dessa indagação que se organizou a natureza e a metodologia desta pesquisa que podemos definir como uma pesquisa de intervenção pedagógica em uma escola pública no interior do Estado de São Paulo, com conteúdos escolares clássicos de Taxonomia e Sistemática Biológica na perspectiva Histórico-crítica e, portanto, dentro de uma concepção de mundo materialista histórico-dialética.

Em um primeiro momento, pela constante necessidade de elaboração, avaliação e reformulação teórica que implica a Pedagogia Histórico-crítica, buscamos elencar o que 
chamamos neste trabalho de "Princípios norteadores da prática pedagógica na Pedagogia Histórico-crítica".

Ou seja, antes, durante o desenvolvimento do trabalho e nas análises posteriores da intervenção pedagógica elaborada baseamos nos acentos teóricos em Marx e princípios indicados pela fundamentação Marxista explicitados em vários momentos das obras de Saviani $(2005,2008,2013)$ e, outros fundamentos teóricos para a organização da prática pedagógica, descritos e discutidos por autores como Oliveira (1994); Della Fonte (2011); Duarte (2012, 2013); Marsiglia (2013), a qual já aproveito o espaço para agradecimento pela participação como banca desta tese.

Também participaram desta revisão bibliográfica todos aqueles trabalhos do ensino de Ciências para compreendermos, como campo de conhecimento que é específico da PHC, o que é específico do ensino de Ciências, o que é específico do ensino de Biologia.

Assim sendo, consideramos como essenciais a qualquer prática pedagógica nessa perspectiva os seguintes princípios relacionados: o conceito de homem; a luta de classes e alienação; o conceito de educação e a especificidade da escola; e a mediação. Com relação à prática pedagógica específica no ensino de Biologia apontamos, ainda, dois princípios: a relação entre os conteúdos clássicos e os conteúdos científicos da área; e o conceito de ciência e o caráter mutável do conhecimento.

Então, compreendemos que para abordar a Taxonomia e Sistemática Biológica, mesmo dentro de sua especificidade, teríamos que passar obrigatoriamente por essas questões: o ser humano, trabalhar conteúdos de luta de classe, alienação, a classificação como atividade científica e própria do ser humano, os conteúdos clássicos e científicos da área de sistemática e a ciência como campo de conhecimento não neutro e dinâmico, em constante reformulação. Em outras palavras, trabalhar que esse conhecimento biológico se altera, abordar todo o processo histórico do conteúdo clássico da taxonomia, como ela surgiu e para onde ela está caminhando até agora.

Deste ponto encontramos as primeiras dificuldades, pois, depois que nós fizemos todo esse levantamento teórico, ficava cada vez mais clara a de se fazer um cuidadoso levantamento dos trabalhos já produzidos da Pedagogia histórico-crítica e do ensino de ciências.

Já de início encontramos um trabalho desenvolvido por um grupo do ensino de química (ZILLI et al., 2015) para o Encontro Nacional de Pesquisa em Educação em Ciências, ENPEC, 
que visou explorar as contribuições da Pedagogia Histórico-crítica para o ensino de Ciências também por meio de levantamento bibliográfico.

Nesse trabalho, Zilli et al. (2015) consultaram as nove edições do Encontro Nacional de Pesquisa em Educação em Ciências (ENPEC), periódicos nacionais dedicados ao Ensino de Ciências e os livros escritos sobre a temática, ambos no período de 1997 a 2014.

Utilizando-se de metodologia semelhante ao levantamento acima citado (ZILLI et al., 2015) expandimos a busca pelo termo "Pedagogia Histórico-crítica" nas palavras-chaves e títulos, nas edições de 2015 e 2016 das revistas e ENPEC seguintes, elencando a totalidade dos trabalhos. Ampliando ainda mais a pesquisa, buscando um mapeamento de todos os termos "Histórico-crítica" e "Ciências" em título, resumo e palavras-chaves na totalidade do banco de $\operatorname{artigos}^{2}$.

O que parece ser um extenso mapeamento acabou revelando uma realidade fácil de análise: considerando o vínculo real entre ensino de ciências e Pedagogia histórico-crítica estavam em apenas 17 trabalhos. Do campo de estudo específico da Biologia, apenas cinco. Outra coisa, dos trabalhos de ensino de ciências elencados, seis deles eram, inclusive, de um mesmo grupo de pesquisa publicados no mesmo evento [Universidade Federal da Bahia no ENPEC de 2015], ou seja, a produção do ensino de ciências e pedagogia histórico crítica mostrou-se muito incipiente.

Mais ainda, dos trabalhos analisados, poucos citam diretamente Vygotsky e apenas um trabalho elucidava a teoria marxista e citava o materialismo histórico dialético.

Pudemos constatar, nos trabalhos analisados, que o ensino de Ciências não está aprofundando no materialismo histórico dialético como já indicado pela literatura. Fala-se de uma pedagogia e de um pensamento crítico, mas pouco se embasa ou se aprofunda nessa discussão. Então, volto à defesa da rigorosidade e comprometimento teórico do marxismo no ensino de ciências.

Posterior a esse momento de organização da pesquisa, planejei as intervenções didáticas, que duraram cerca de três meses, em uma turma de terceiro ano do Ensino Médio de uma escola pública estadual, de uma cidade do interior do estado de São Paulo, na qual eu acompanhei como professora efetiva de Biologia.

Todas as aulas ministradas no período foram gravadas e transcritas para serem utilizadas como instrumento de pesquisa e análise. Ao final do ano letivo, também foram realizadas

\footnotetext{
${ }^{2}$ Busca realizada em Scielo (http://www.scielo.org).
} 
entrevistas semiestruturadas com alunos que aceitaram participar voluntariamente do procedimento.

A Entrevista levou em consideração os objetivos de pesquisa: a definição de ciência; a definição do que é a Biologia; e o pensamento dos alunos a respeito da escola e da sua própria formação escolar. Mas mais do que isso gostaríamos de identificar qual a percepção dos alunos perante à perspectiva crítica de educação.

Já a elaboração das intervenções didáticas levou em consideração esses três temas: "Sistema de classificação biológica, sistemática e taxonomia"; "O conceito de espécie" e "A espécie humana”. Foram esses três eixos, as três temáticas programadas que levariam, para seu desenvolvimento, cerca de nove aulas.

Esse trabalho tem como metodologia de pesquisa a dialética materialista como concepção; método de análise e/ou como práxis. Isso significa uma exaustiva análise crítica do produzido, a seleção de unidades de análise em tensão que lhe permitem entender melhor este objeto e apreender o concreto real e suas multideterminações.

Acabamos percebendo que optar pelo conteúdo clássico era, na verdade, voltar às questões de para quem e para quê eu estava dando aquele conteúdo, qual era o enfoque que eu deveria trabalhar.

Percebemos que o enfoque a ser utilizado para uma intervenção didática plausível com a PHC o enfoque a ser seguido deveria estar em acordo com o enfoque dialético, já descartando totalmente o enfoque tipológico medieval que o popular "caderninho", o material didático padrão, traz das espécies.

Para quem não é da área da biologia ou do ensino de ciências, o tal "caderninho" traz muito a ideia das espécies fixas, da necessidade de considerar determinadas características dos seres vivos e classificarem por meio dessas características. Essa é a visão tipológica e essencialista de espécie trazida pelo material, que considera as espécies como um grupo constante, imutável e arbitrário, pois desconsideram os processos evolutivos.

Entendemos que não há, de forma alguma, como discutir os conteúdos clássicos biológicos, entre eles a espécie humana, sem descartar a compreensão essencialista e prédeterminada de espécie que o material didático padrão traz.

Por exemplo, para o conceito de espécie, esse tipo de material didático deixa muito claro que o conceito de espécie pode ser definido como grupo de indivíduos que podem se intercruzar e gerar descendentes férteis. 
Para a biologia, essa é uma proposição correta? Sim, ela pode ser considerada por correta, mas ela desconsidera uma porção de exceções, uma porção de proposições que devem ser consideradas, que passavam no caderninho como se não fossem notadas.

Como objetivo de aula, para além da apresentação do conceito biológico de espécie, a exemplo das espécies híbridas, se objetivou a apropriação do enfoque evolutivo do conceito biológico de espécie.

E mais do que isso, se considerou a dimensão científica do conceito e exposição das particularidades presentes neste tema, a apropriação do caráter mutável do conhecimento rumo à compreensão de ciência não neutra.

Então, o objetivo da prática avaliativa era compreender como os alunos desenvolveriam um conhecimento mais sintético e elaborado, ou seja, como possibilitar entre os alunos a passagem de um estágio de menor compreensão a uma fase de maior clareza e entendimento dentro da totalidade.

Questionou-se entre os alunos: Para que nós precisamos classificar os seres vivos? Para o que nós precisamos considerar o enfoque evolutivo como o enfoque correto para visualizar esses seres vivos? Ou seja, mostrar que a natureza é muito mais rica, a variedade, a sua mudança constante, do que simplesmente apresentar os indivíduos, os seres, como seres imutáveis.

Isso já traz uma visão de mundo atrás de cada um desses conteúdos. Ao observar a superação da essência metafísica do enfoque tipológico de espécie, no qual os indivíduos são arbitrariamente ideais, constantes, imutáveis estamos falando de mudança de concepção de mundo tendo o conteúdo científico como ferramenta.

Deste ponto, já se inicia análise dos dados.

Mas inicio essa análise me defendendo de uma primeira crítica que possa surgir: “Ah, mas você considerou isso e conseguiu desenvolver toda perspectiva histórico-crítica no ensino de Biologia porque se tratava do Ensino Médio".

Eu escolhi Ensino Médio propositalmente. Eram anos que estavam caminhando comigo desde o Ensino Fundamental, conheciam meu trabalho e já tinham essa perspectiva crítica aguçada dentro deles, porque foi esse o trabalho que eu tive com esses alunos. Então, não foi uma escolha despropositada.

Mas queria ressaltar aqui que, se a pedagogia crítica fosse só possível no Ensino Médio, nós estaríamos indo pelo caminho do construtivismo que considera que existem fases de 
desenvolvimento em que é possível ou não um desenvolvimento de uma habilidade ou competência específica. Nós descartamos essa ideia.

Trabalhar com a Pedagogia histórico-crítica não é uma questão de apenas se considerar a fase do desenvolvimento em que se encontram os alunos. Pelo contrário, repudiamos o ideário construtivista de desenvolvimento humano, que compreende que caso não haja condições biológicas para se reestabelecer o equilíbrio rumo a uma dimensão mais ampla, ou seja, caso o indivíduo não atinja certo grau de desenvolvimento intelectual, não é capaz de avançar além desses limites e ultrapassar a sua própria possibilidade biológica.

Afinal, tal como apontado por Vygotsky, a aprendizagem antecede o processo de maturação do indivíduo. E, segundo, porque ensinar se trata da transmissão consciente do saber sistematizado e, portanto, tem objetivos claramente pré-definidos e não se dá de maneira espontânea, mas, sim, ocorre fundamentado em condições histórico-sociais de transmissão de conteúdos e de mediação, isto é, do próprio processo de ensino

Então, a primeira defesa, a primeira contribuição que eu quero trazer da minha pesquisa no ensino de Ciências e provocar pesquisas no ensino de Ciências é a de que a Pedagogia histórico-crítica é possível em qualquer fase de desenvolvimento.

Outro ponto que defendo: a PHC é possível para todos os conteúdos. Ou seja, é possível trabalhar o ensino de Biologia em uma perspectiva histórico-crítica em todos os conteúdos, até mesmo naqueles em que o científico parece se distanciar da esfera social imediata.

Se fosse uma questão de alguns conteúdos serem possíveis e outros não, nós estaríamos, já de início, com uma pedagogia furada.

A escolha do conteúdo a ser trabalhado não se trata da identificação de uma problemática qualquer capaz de ter uma repercussão ética ou social imediata, de problemas a serem solucionados no contexto do cotidiano. Então, não se trata de uma questão de escolha de conteúdos e sim uma questão de como eu abordo esses conteúdos, quais os objetivos de aprendizagem que esses conteúdos carregam.

A PHC está relacionada com os objetivos tratados na prática pedagógica e na compreensão de mundo.

Se formos para um caminho em que as espécies são fixas, que os seres humanos são apenas aqueles seres descritos com telencéfalo desenvolvido e polegar opositor, não há mais o que se discutir do que nos difere das demais espécies animais. No entanto, é possível perguntar: quais outras particularidades do ser humano que devem ser abordadas no ensino de Ciências? 
Outra pergunta capaz de surgir é: é possível trabalhar PHC em um contexto problemático? Porque eu vejo que muitos ficam se questionando se no dia a dia, na sala de aula, no meu caso, em uma escola periférica, cujo abandono é bastante alto, gravidez precoce altíssima. E defendo: é possível trabalhar o ensino de Biologia em uma perspectiva históricocrítica em qualquer contexto. Basta querer, estudar, estudar mais um pouco e ir encontrando, ali com os alunos, os caminhos.

Por fim, só para provocar vocês. A metodologia de pesquisa utilizada aqui é a dialética materialista. Eu usei a dialética materialista como compreensão de mundo, como estratégia metodológica e como fundamentação teórica, que permeou todo o trabalho.

Como toda a teoria marxista dialética, se buscou trazer uma exaustiva análise de todo o material produzido, da seleção das unidades de análise encontradas e discutidas, tentando resolver essas problemáticas que eu fui encontrando e por fim, a transformação da realidade.

Se a pedagogia histórico-crítica não fosse possível em qualquer contexto, então não teria contexto a ser mudado. É justamente no contexto problemático que a Pedagogia históricocrítica ganha força, a partir da necessidade de transformação e mudança.

Todas essas aulas que eu preparei e desenvolvi foram realizadas em 2015 com meus alunos. No mês de setembro de 2015, foi divulgado o que seria chamado de a reformulação da Rede estadual do estado paulista, em que as escolas seriam remanejadas, se tornariam escolas de ciclo único. Ou seja, para o ano letivo de 2016, as escolas passariam a ser exclusivamente de anos iniciais do Ensino Fundamental, anos finais do Ensino Fundamental ou apenas de Ensino Médio.

A escola em que desenvolvi esse trabalho seria uma das escolas afetadas no processo. Ela deixaria de ser uma escola de Fundamental II e Ensino Médio para apenas receber alunos do Ensino Médio. Demais alunos seriam remanejados e encaminhados para escolas mais distantes. Outras escolas desta mesma cidade do interior, também poderiam ser seriam fechadas nessa organização.

Então, nesse contexto no ensino de Biologia, discutindo classificação, espécie, discutindo taxonomia, que alunos se organizaram para questionar essa reorganização e transformamos essa realidade. À medida que se mobilizaram, tomaram a frente de manifestos, abaixo-assinados, se articularam politicamente e ainda cobraram posicionamento dos demais professores e gestores inicialmente apáticos à proposta de reorganização. 
Mesmo que esse movimento não tenha sido pontual e tenha acontecido em todo o Estado de São Paulo, termino essa apresentação apresentando a possibilidade de transformação. Afinal, após inúmeros protestos populares nos três meses consecutivos, a proposta foi posteriormente cancelada.

Então esse trabalho também é um relato de que é possível superar sim os mecanismos que regem a organização e funcionamento do sistema educacional brasileiro, em busca da transformação da realidade, e este é um ponto chave que devemos ter em mente em busca da superação do conformismo que impera no discurso intra-escolar.

\section{Referências}

CAMPOS, R. S. P. A Pedagogia Histórico-crítica e prática docente de ensino de Biologia. 2017. 181 f. Tese (Doutorado em Educação para Ciência) - Faculdade de Ciências, Universidade Estadual Paulista, Bauru, 2017.

CAMPOS, R. S. P. Ensino de ciências e de biologia sob a perspectiva histórico- crítica na literatura científica. Debates em Educação, Maceió, v. 12, n. 26, p. 225-241, 2020. Disponível em: http://dx.doi.org/10.28998/2175-6600.2020v12n26p225-241. Acesso em:

DELLA FONTE, S. S. Fundamentos teóricos da Pedagogia Histórico-Crítica. In: MARSIGLIA, A. C. G (org.). Pedagogia Histórico-crítica: 30 anos. Campinas: Autores Associados, 2011. p. 23-42.

DUARTE, N. Vigotski e o "aprender a aprender": crítica às apropriações neoliberais e pósmodernas da teoria vigotskiana. 5. ed. Campinas: Autores Associados, 2012.

DUARTE, N. A individualidade para si. Campinas: Autores Associados, 2013.

LIPORINI, T. Q. O ensino de sistemática e taxonomia biológica no ensino médio da rede estadual no município de São Carlos - SP. 2016. 202 f. Dissertação (Mestrado em Educação para a Ciência) - Universidade Estadual Paulista, Faculdade de Ciências, Bauru, 2016.

MARSIGLIA, A. C. G. Contribuições para os fundamentos teóricos da prática pedagógica histórico-crítica. In: MARSIGLIA, A. C. G. Infância e pedagogia histórico-crítica.

Campinas: Autores Associados, 2013.p.213-245

OLIVEIRA, B. A. Fundamentação marxista do pensamento de Dermeval Saviani. SILVA JÚNIOR, C. A. S. (org.). Dermeval Saviani e a educação brasileira: o simpósio de Marília. São Paulo: Cortez Editora, 1994. p. 105-128.

SAVIANI, D. Educação Brasileira: estrutura e sistema. 9. ed. Campinas: Autores Associados, 2005.

SAVIANI, D. Pedagogia histórico-crítica: primeiras aproximações. 10. ed. Campinas: Autores Associados, 2008.

SAVIANI, D. Educação: do senso comum à consciência filosófica. Campinas:

Cortez/Autores Associados, 2013. 
ZILLI, B. et al. Apropriação teórica e metodológica da Pedagogia Histórico-Crítica na Educação em Ciências. In: ENCONTRO NACIONAL DE PESQUISA EM EDUCAÇÃO EM CIÊNCIAS, ENPEC, 10., 2015, Águas de Lindóia, SP. Anais [...]. Águas de Lindóia: Associação Brasileira de Pesquisa em Educação em Ciências, ABRAPEC, 2015. 